\title{
The effects of rotation and ice shelf topography on frazil-laden ice shelf water plumes
}

Article

Published Version

Holland, P. R. and Feltham, D. L. (2006) The effects of rotation and ice shelf topography on frazil-laden ice shelf water plumes. Journal of Physical Oceanography, 36 (12). pp. 23122327. ISSN 0022-3670 doi: https://doi.org/10.1175/JPO2970.1 Available at https://centaur.reading.ac.uk/34907/

It is advisable to refer to the publisher's version if you intend to cite from the work. See Guidance on citing.

Published version at: http://dx.doi.org/10.1175/JPO2970.1

To link to this article DOI: http://dx.doi.org/10.1175/JPO2970.1

Publisher: American Meteorological Society

All outputs in CentAUR are protected by Intellectual Property Rights law, including copyright law. Copyright and IPR is retained by the creators or other copyright holders. Terms and conditions for use of this material are defined in the End User Agreement.

www.reading.ac.uk/centaur

\section{CentAUR}


Central Archive at the University of Reading

Reading's research outputs online 


\title{
The Effects of Rotation and Ice Shelf Topography on Frazil-Laden Ice Shelf Water Plumes
}

\author{
Paul R. Holland* And Daniel L. Feltham ${ }^{+}$ \\ Centre for Polar Observation and Modelling, University College London, London, United Kingdom
}

(Manuscript received 24 June 2005, in final form 20 April 2006)

\begin{abstract}
A model of the dynamics and thermodynamics of a plume of meltwater at the base of an ice shelf is presented. Such ice shelf water plumes may become supercooled and deposit marine ice if they rise (because of the pressure decrease in the in situ freezing temperature), so the model incorporates both melting and freezing at the ice shelf base and a multiple-size-class model of frazil ice dynamics and deposition. The plume is considered in two horizontal dimensions, so the influence of Coriolis forces is incorporated for the first time. It is found that rotation is extremely influential, with simulated plumes flowing in near-geostrophy because of the low friction at a smooth ice shelf base. As a result, an ice shelf water plume will only rise and become supercooled (and thus deposit marine ice) if it is constrained to flow upslope by topography. This result agrees with the observed distribution of marine ice under Filchner-Ronne Ice Shelf, Antarctica. In addition, it is found that the model only produces reasonable marine ice formation rates when an accurate ice shelf draft is used, implying that the characteristics of real ice shelf water plumes can only be captured using models with both rotation and a realistic topography.
\end{abstract}

\section{Introduction}

Floating ice shelves provide an important interface between grounded ice sheets and the ocean's changing climate. It is not certain that a warming ocean will increase net basal melt from the largest shelves (Nicholls 1997), but increased oceanic melting is thought to be implicated in the thinning and collapse of smaller ice shelves around Antarctica and Greenland (Shepherd et al. 2003, 2004; Thomas 2004). The removal of mass from these shelves seems to result in acceleration and thinning of their tributary ice streams, leading to sea level rise (De Angelis and Skvarca 2003; Joughin et al. 2004; Payne et al. 2004). Interaction between ice shelves and the ocean has a strong influence on the

\footnotetext{
* Current affiliation: British Antarctic Survey, Cambridge, United Kingdom.

+ Current affiliation: Centre for Polar Observation and Modelling, London, and British Antarctic Survey, Cambridge, United Kingdom.
}

Corresponding author address: Dr. Paul R. Holland, British Antarctic Survey, High Cross, Madingley Road, Cambridge CB3 OET, United Kingdom.

E-mail: p.holland@bas.ac.uk properties of several Antarctic water masses (Rivaro et al. 2003; Foldvik et al. 2004), which are precursors to Antarctic Bottom Water-the most ubiquitous water mass in the world and a key driver of the global thermohaline circulation (Orsi et al. 1999). Melting and freezing at the base of ice shelves is therefore of importance to the mass balance of the cryosphere and the circulation of the world's oceans.

Seawater's freezing temperature decreases with increasing pressure and therefore depth, so water at the surface freezing temperature [such as high-salinity shelf water (HSSW)] becomes superheated (warmer than the in situ freezing temperature) as it descends and intrudes into a subshelf cavity, gaining the potential to melt the ice shelf base. The released meltwater cools and freshens the ambient seawater to form a water mass, which is colder than the surface freezing temperature, known as ice shelf water (ISW). This ISW subsequently flows along the base of the ice shelf under the influence of buoyancy, frictional, and Coriolis forces, continually entraining the ambient seawater. If an ISW plume rises then the increase in local freezing temperature may cause it to become supercooled and start to freeze, both directly at the ice shelf base and (much more efficiently) through the formation of frazil (tiny discshaped ice crystals). These crystals may settle out of the 


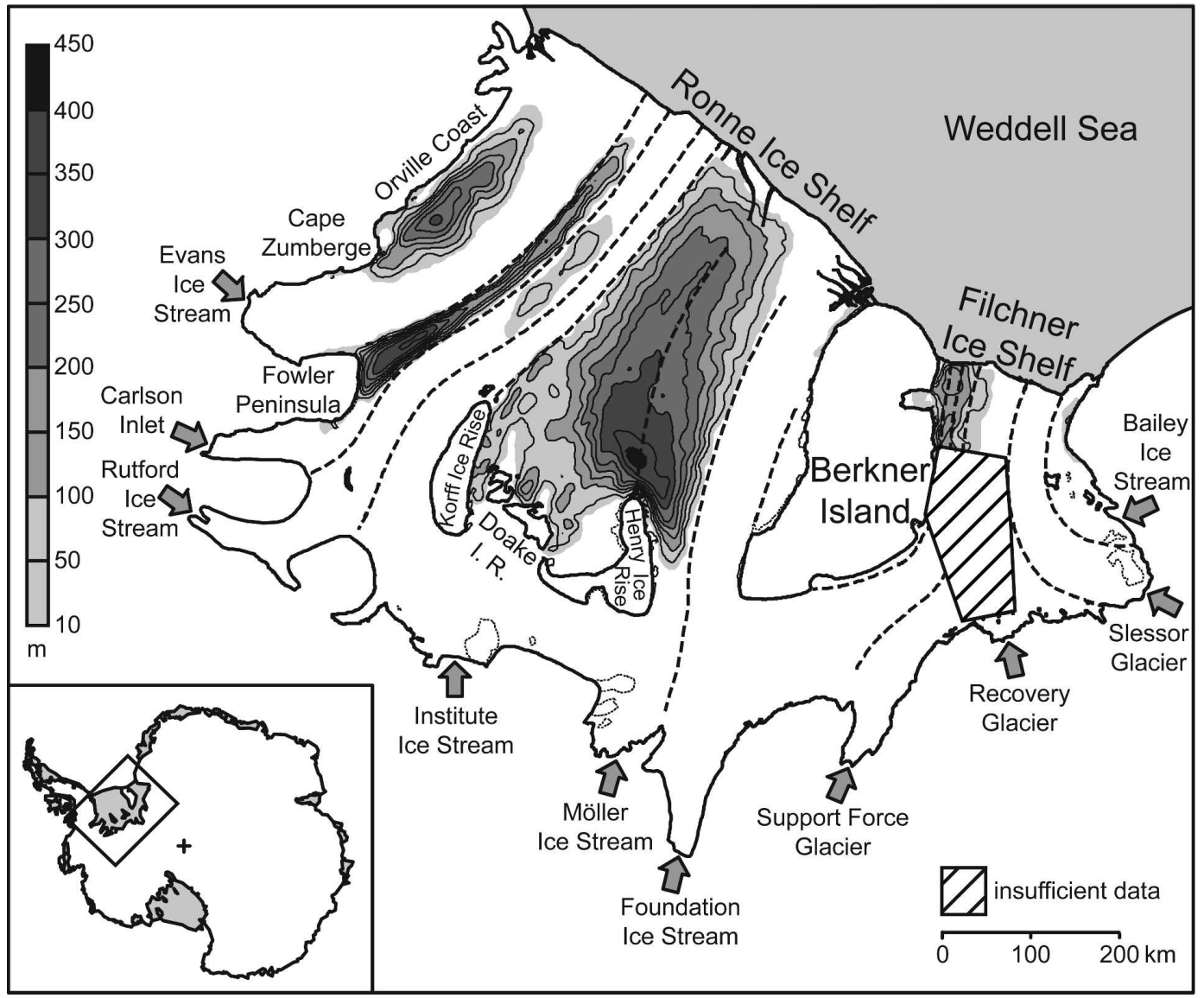

FIG. 1. Map of marine ice thickness at the base of Filchner-Ronne Ice Shelf (after Sandhäger et al. 2004).

plume onto the ice shelf and, in combination with direct freezing, this causes the accretion of large areas of basal marine ice (Oerter et al. 1992). The cycle of melting at depth and refreezing in shallower areas because of freezing temperature variation is called the "ice pump" (Lewis and Perkin 1983; Jenkins and Bombosch 1995).

The dynamics of ISW plumes have been the subject of many specialized modeling studies (MacAyeal 1985; Hellmer and Olbers 1989; Jenkins 1991; Nøst and Foldvik 1994), but frazil ice dynamics in ISW plumes have so far only been studied by Holland and Feltham (2005) and in the one-dimensional depth-averaged models of Jenkins and Bombosch (1995) and Smedsrud and Jenkins (2004, hereinafter SJ04), who produced a good spatial agreement with basal melting and freezing rates inferred from observation (Joughin and Padman 2003). The dynamics of the majority of these models are limited in that the path taken by each plume must be chosen beforehand.

Several different general circulation models (GCMs) have been applied to the ocean cavity beneath ice shelves (Grosfeld et al. 1997; Beckmann et al. 1999;
Holland and Jenkins 1999). None has yet included a model of the formation or deposition of frazil ice, which accounts for the majority of marine ice deposition and influences ISW plume thermodynamics (SJ04). The introduction of frazil ice into these models is limited by the heavy computational load of the small time step required to properly capture the rapid evolution of frazil populations. In addition, GCMs are necessarily applied at relatively coarse horizontal resolution, so they are unable to represent the finer detail of ISW plume flow.

ISW plumes are particularly important under Filchner-Ronne Ice Shelf (FRIS), Antarctica, the most voluminous ice shelf on Earth (Fig. 1). In winter, brine rejection from sea ice formation in the Weddell Sea generates HSSW, which sinks under FRIS and melts its grounding line at depths of up to $2000 \mathrm{~m}$ (Lambrecht et al. 1999). The resulting ISW plumes influence ocean properties in the cavity (Nicholls and Østerhus 2004) and lay down thick deposits of marine ice in shallower areas of the shelf (Fig. 1), redistributing the ice shelf's mass. 
The aim of this paper is to examine in detail the effects of both Coriolis force and ice shelf basal topography on ISW plumes and their marine ice deposition. This is accomplished by incorporating frazil ice dynamics and ocean-ice shelf interaction into an unsteady plume model that is two-dimensional in the horizontal plane. Such a model has the advantage of being able to represent Coriolis forces while still being computationally inexpensive enough to be run at high spatial resolution with frazil ice included. However, because the model consists of a single active layer, we are unable to model the potentially important effects of eddyforming processes or barotropic flow. Our study shows that frazil ice deposition accounts for approximately 10 times more marine ice formation than direct freezing. We consider transient effects, a realistic two-dimensional ice shelf draft, and the full horizontal momentum balance governing frazil-laden ISW flow for the first time.

In the remainder of this paper, we present a discussion of the model (section 2) and a range of model results (section 3). We initiate the results section by reducing our model to a one-dimensional formulation comparable to that of SJ04, so that we can test our model developments against a well-understood benchmark. Next, we elucidate the basic effects of rotation on a two-dimensional plume flowing under a generalized wedge-like ice shelf topography. For clarity, we then apply the model to a simplified ice shelf geometry representative of the Evans Ice Stream (EIS) section of FRIS (Fig. 1), where our predictions of frazil ice deposition locations agree with measured areas of marine ice. After examining the sensitivity of our results to the variation in key parameters in this simple domain, we introduce a real FRIS ice shelf draft to test the model's prediction of marine ice formation rates. In section 4 we discuss the implications of our findings for the flow of meltwater under the rest of FRIS.

\section{Mathematical model and simplifications}

\section{a. Model overview}

The ISW plume is simulated by combining a parameterization of ice shelf basal interaction and a multiplesize-class frazil dynamics model with an unsteady, depth-averaged, reduced-gravity plume model. In the model an active region of ISW evolves above and within an expanse of stagnant ambient fluid, which is considered to be ice free and has fixed profiles of temperature and salinity. The primary aim of this study is to isolate Coriolis effects, so we neglect (horizontal) spatial heterogeneity of the ambient fluid. The horizontal extent of the active plume is determined by a simple

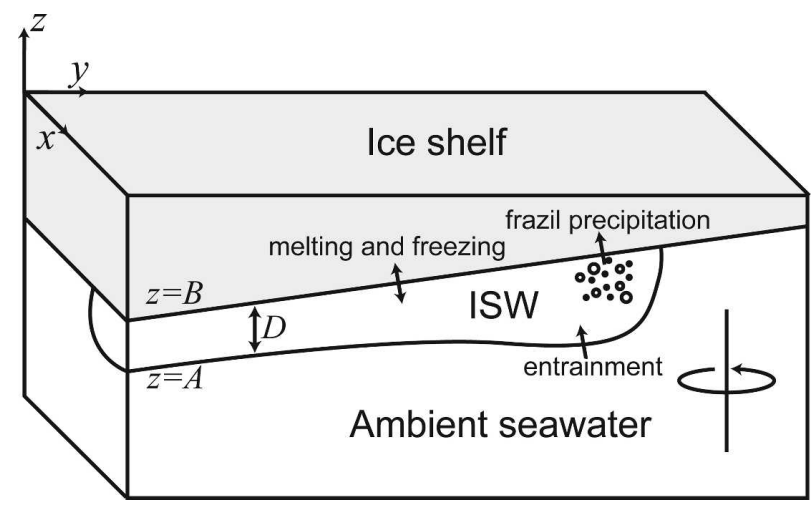

FIG. 2. Definition of coordinates and schematic of relevant processes.

"wetting and drying" scheme based on the slope of the interface between the plume and ambient fluid (Jungclaus and Backhaus 1994).

ISW is treated as a mixture of seawater and frazil ice crystals. The frazil ice concentration $C$ is the total ice volume per unit mixture volume and is distributed between $N_{\text {ice }}$ size classes such that $C=\sum_{i=1}^{N_{\text {ice }}} C_{i}$. Frazil crystals are treated as circular discs, and each class is defined by a fixed crystal radius so that growth or melting results in a transfer of mass between classes. In addition to frazil growth, melting, and precipitation, we model the process of secondary nucleation, whereby new frazil nuclei form from existing ice crystals.

Depth-averaged velocities in Cartesian coordinates $x$ and $y$ are denoted $U$ and $V$, which are in the horizontal cross-shelf and horizontal along-shelf (parallel to glaciological flow) directions, respectively (Fig. 2); $z$ is the vertical coordinate, taken to be positive upward from mean sea level; $A$ and $B$ are the positions of the ambient-plume and ice shelf-plume interfaces, respectively, and $D$ is the plume depth. The ice shelf-plume interface $B$ is treated as fixed, regardless of any melting and freezing that takes place.

To initiate the plume, we assume that basal melting at the ice shelf's grounding line resulting from an intrusion of HSSW generates a mixed layer of ISW with a fixed depth. This mixed layer has the properties of a water mass made up of equal parts of the ambient seawater and the meltwater, which itself has properties calculated by considering the melting of ice in the ambient seawater according to the model of Gade (1979). The ISW is then allowed to evolve until either the plume density matches that of the ambient fluid or the plume flows out of the open boundaries of the computational domain. In the former case the plume should separate from the shelf and flow out into the ambient fluid, a process that we are unable to model using this 
formulation. In the latter case we are able to continue the model run until a steady state is found for the part of the plume that remains in the domain.

\section{b. Governing equations}

The plume is considered to be a two-component mixture of ice and seawater that is treated as a homogeneous fluid with averaged properties (Jenkins and Bombosch 1995). The density of the mixture is

$$
\rho_{m}=\rho+C\left(\rho_{I}-\rho\right),
$$

where $\rho_{I}=920 \mathrm{~kg} \mathrm{~m}^{-3}$ is the ice density and the seawater density $\rho$ is described by a linearized equation of state,

$$
\rho=\rho_{0}\left[1+\beta_{S}\left(S-S_{0}\right)-\beta_{T}\left(T-T_{0}\right)\right],
$$

where $\rho_{0}=1030 \mathrm{~kg} \mathrm{~m}^{-3}, T_{0}=-2.0^{\circ} \mathrm{C}, S_{0}=34.5 \mathrm{psu}$, $\beta_{S}=7.86 \times 10^{-4} \mathrm{psu}^{-1}$, and $\beta_{T}=3.87 \times 10^{-5}{ }^{\circ} \mathrm{C}^{-1}$ (Jenkins and Bombosch 1995).

Applying the Boussinesq approximation to the water fraction and integrating over the plume depth, we obtain a volume conservation equation for the mixture of frazil and seawater,

$$
\frac{\partial D}{\partial t}+\boldsymbol{\nabla} \cdot(D \mathbf{u})=e^{\prime}+m^{\prime}+p^{\prime},
$$

where $\boldsymbol{\nabla}=(\partial / \partial x, \partial / \partial y), \mathbf{u}=(U, V)$, and $e^{\prime}, m^{\prime}$, and $p^{\prime}$ are the rates of entrainment, basal melting, and frazil precipitation, respectively (Fig. 2). When considering the individual seawater and frazil fractions, we must also take into account the diffusive effect of the turbulent mixing of frazil crystals, which we assume has no effect on the overall mixture volume (Holland and Feltham 2005). The volume conservation equations for seawater and frazil ice (in each size class), respectively, are therefore

$$
\begin{aligned}
\frac{\partial[(1-C) D]}{\partial t}+\boldsymbol{\nabla} \cdot[(1-C) D \mathbf{u}]= & \boldsymbol{\nabla} \cdot\left[K_{h} D \boldsymbol{\nabla}(1-C)\right] \\
& +e^{\prime}+m^{\prime}+f^{\prime}
\end{aligned}
$$

and

$$
\begin{aligned}
\frac{\partial\left(C_{i} D\right)}{\partial t}+\boldsymbol{\nabla} \cdot\left(C_{i} D \mathbf{u}\right)= & \boldsymbol{\nabla} \cdot\left(K_{h} D \nabla C_{i}\right) \\
& +\frac{\rho_{0}}{\rho_{I}}\left(p_{i}^{\prime}+n_{i}^{\prime}-f_{i}^{\prime}\right),
\end{aligned}
$$

where $f^{\prime}$ and $n^{\prime}$ are the rates of frazil melting or freezing and frazil secondary nucleation, respectively. The subscript $i$ denotes the property of an individual frazil size class and lack of a subscript implies summation over all size classes, where applicable. For consistency, all primed variables are defined as rates of seawater transport $\left(\mathrm{m} \mathrm{s}^{-1}\right)$ and are positive when the plume gains mass; $e^{\prime}, m^{\prime}$, and $f^{\prime}$ are positive when the water fraction gains mass, and $p^{\prime}$ and $n^{\prime}$ are positive when the ice fraction (or component thereof) gains mass. The horizontal eddy diffusivity for frazil ice is taken to be the same value as is used for heat and salt, as introduced below.

By assuming the ambient fluid to be stationary and horizontally homogeneous and treating the pressure gradient terms according to Killworth and Edwards (1999), we obtain the depth-integrated Boussinesq Navier-Stokes equations of Jungclaus and Backhaus (1994)

$$
\begin{aligned}
\frac{\partial(D U)}{\partial t}+\boldsymbol{\nabla} \cdot(D \mathbf{u} U)= & \boldsymbol{\nabla} \cdot\left(A_{h} D \boldsymbol{\nabla} U\right)+\frac{g D^{2}}{2 \rho_{0}} \frac{\partial \rho_{m}}{\partial x} \\
& +g^{\prime} D \frac{\partial A}{\partial x}-c_{d} U|\mathbf{u}|+D f V
\end{aligned}
$$

and

$$
\begin{aligned}
\frac{\partial(D V)}{\partial t}+\boldsymbol{\nabla} \cdot(D \mathbf{u} V)= & \boldsymbol{\nabla} \cdot\left(A_{h} D \boldsymbol{\nabla} V\right)+\frac{g D^{2}}{2 \rho_{0}} \frac{\partial \rho_{m}}{\partial y} \\
& +g^{\prime} D \frac{\partial A}{\partial y}-c_{d} V|\mathbf{u}|-D f U .
\end{aligned}
$$

Here the eddy viscosity for momentum $A_{h}$ is assumed to equal $K_{h}, g^{\prime}=\left(\rho_{a}-\rho_{m}\right) g / \rho_{0}$ is the reduced gravity, $\rho_{a}$ is the plume-ambient interface density, $g=9.81$ $\mathrm{m}^{2} \mathrm{~s}^{-1}$ is the gravitational acceleration, and $f$ is the Coriolis parameter. The coefficient $c_{d}$ represents the drag exerted on the current by the stationary ambient fluid in addition to the drag at the ice shelf base.

Extending the scalar transport equations of SJ04 to an unsteady case in which the horizontal turbulent diffusion of heat and salt are not negligible, we arrive at

$$
\begin{aligned}
\frac{\partial(D T)}{\partial t}+\boldsymbol{\nabla} \cdot(D \mathbf{u} T)= & \boldsymbol{\nabla} \cdot\left(K_{h} D \boldsymbol{\nabla} T\right)+e^{\prime} T_{a}+m^{\prime} T_{b} \\
& -\gamma_{T}|\mathbf{u}|\left(T-T_{b}\right)-f^{\prime}\left(\frac{\mathcal{L}}{c_{0}}-T_{f}\right),
\end{aligned}
$$

and (because the salinity of ice is negligible, the source terms from phase changes cancel)

$$
\frac{\partial(D S)}{\partial t}+\boldsymbol{\nabla} \cdot(D \mathbf{u} S)=\boldsymbol{\nabla} \cdot\left(K_{h} D \boldsymbol{\nabla} S\right)+e^{\prime} S_{a} .
$$

Here $T_{a}$ and $S_{a}$ are the temperature and salinity of the ambient fluid at the plume-ambient interface, $\mathcal{L}=$ $3.35 \times 10^{5} \mathrm{~J} \mathrm{~kg}^{-1}$ is the latent heat of ice fusion, and $c_{0}=3974 \mathrm{~J} \mathrm{~kg} \mathrm{~g}^{-1}{ }^{\circ} \mathrm{C}^{-1}$ is the specific heat capacity of seawater; $T_{f}$ is the pressure freezing temperature at the 
middepth of the plume, $T_{b}$ is the temperature at the interface between ice shelf and ocean, and $\gamma_{T}$ is a coefficient representing the transfer of heat in the adjacent boundary layer.

\section{c. Entrainment}

The entrainment parameterization used in previous ISW plume models is a simplified version of the formula derived by Bo Pederson (1980) for steam-tube models. Jungclaus and Backhaus (1994) found that a more realistic behavior throughout a horizontally varying plume could be achieved by using the Kochergin (1987) formulation, which explicitly represents the relative strengths of shear production and stability suppression of turbulence,

$$
e^{\prime}=\frac{c_{l}^{2}}{\mathrm{Sc}_{T}} \sqrt{\left(U^{2}+V^{2}\right)\left(1+\frac{\mathrm{Ri}}{\mathrm{Sc}_{T}}\right)}
$$

where $\mathrm{Ri}=g^{\prime} D /\left(U^{2}+V^{2}\right)$ is the Richardson number, and we choose $c_{l}$ to be the value that produces a plume that becomes supercooled and deposits frazil ice in the correct position. The turbulent Schmidt number $\mathrm{Sc}_{T}$ is given by the formula of Mellor and Durbin (1975),

$$
\mathrm{Sc}_{T}=\frac{\mathrm{Ri}}{0.0725\left(\mathrm{Ri}+0.186-\sqrt{\mathrm{Ri}^{2}-0.316 \mathrm{Ri}+0.0346}\right)} .
$$

As shown by Jungclaus and Backhaus (1994), the entrainment formulation given by (10) and (11) produces similar behavior to that of Bo Pederson (1980), with the entrainment rate decreasing with increasing $\mathrm{Ri}$. The two formulations only differ near the very shallow edges of the plume, where the formulation we adopt gives a more realistic lower value.

\section{d. Drag}

The choice of drag coefficient is important because in this model formulation friction is the only force that breaks geostrophy and causes plumes to flow upslope and become supercooled. This is partly a result of depth averaging, which neglects the details of flow in an Ekman layer next to the ice shelf in which viscous forces are important and upslope "draining" of fluid should occur (Cenedese et al. 2004). More importantly, this formulation neglects the presence of eddies in the plume, which have been observed to transfer fluid downslope in several studies of bottom-trapped dense water plumes (Jiang and Garwood 1995; Lane-Serff and Baines 1998). Unfortunately, we are unable to model the formation processes of these eddies (baro- clinic instability and vortex stretching in the ambient fluid) with the single-layer model employed here.

Form drag at the seabed is usually simulated in numerical ocean models by adopting the quadratic drag terms in (6) and (7) with a $c_{d}$ value of order $10^{-3}$, matching values inferred from observation (Ramming and Kowalik 1980). In contrast, simplified plume models applied to idealized "wedge" bathymetries require $c_{d}$ to be orders of magnitude larger in the rotating case in order to force the plume to flow downslope far enough to match observations (Killworth 1977; Bo Pederson 1980; Jungclaus and Backhaus 1994). The model adopted here has been used to demonstrate that quantitatively correct downslope propagation can be achieved with $c_{d}=3 \times 10^{-3}$ if a realistic bathymetry is used (Jungclaus and Backhaus 1994; Jungclaus et al. 1995).

Unfortunately, the basal roughness of ice shelves is currently an unknown quantity. Previous authors have used a drag coefficient of $2.5 \times 10^{-3}$, a choice that can be traced back to early examination of the roughness of grassland on Salisbury Plain in the United Kingdom (Taylor 1920; Ramming and Kowalik 1980; MacAyeal 1984, 1985).

Despite basal crevassing, ice shelf bases are generally thought to be smooth because of the effects of melting and ice pumping. For this reason, the drag coefficient at an ice shelf base should be lower than that used to represent the seabed, so the value of $1.5 \times 10^{-3}$ adopted by Holland and Jenkins (1999) and Holland and Feltham (2005) is used here. In sections $3 \mathrm{c}$ and $3 \mathrm{e}$ of this study we demonstrate that this value is reasonable by fitting the deposition zone of our predicted plume to observations of basal freezing (Joughin and Padman 2003) and marine ice deposition patterns (Sandhäger et al. 2004). We note, however, that there are instability mechanisms that could cause corrugations to form on the underside of an ice shelf (Ashton and Kennedy 1972; Feltham and Worster 1999); insufficient information is available to quantify these effects at this time.

\section{e. Basal melting and freezing}

To calculate the basal melt rate $m^{\prime}$, we formulate balances of heat and salt at the ice shelf-plume boundary (Jenkins and Bombosch 1995),

$$
\begin{aligned}
c_{0} \gamma_{T}|\mathbf{u}|\left(T-T_{b}\right) & =m^{\prime} \mathcal{L}+m^{\prime} c_{I}\left(T_{b}-T_{I}\right) \text { and } \\
\gamma_{S}|\mathbf{u}|\left(S-S_{b}\right) & =m^{\prime} S_{b},
\end{aligned}
$$

where $c_{I}=2009 \mathrm{~J} \mathrm{~kg}^{-1}{ }^{\circ} \mathrm{C}^{-1}$ is the specific heat capacity of ice; $T_{I}=-25^{\circ} \mathrm{C}$ is the core temperature of the ice shelf, a value appropriate to FRIS (Jenkins 1991); $S_{b}$ is 
the interface salinity; and $\gamma_{S}$ is the salt transfer coefficient in the boundary layer. The third term in (12) is an approximation of heat conduction within the ice shelf according to Holland and Jenkins (1999); we assume that salt does not diffuse through the ice. The interface quantities $T_{b}$ and $S_{b}$ are constrained by a linearized pressure freezing temperature relation (also used for $T_{f}$ )

$$
T_{b}=a S_{b}+b-c B,
$$

where $a=-0.0573^{\circ} \mathrm{C} \mathrm{psu}^{-1}, b=0.0832^{\circ} \mathrm{C}$, and $c=$ $-7.61 \times 10^{-4}{ }^{\circ} \mathrm{C} \mathrm{m}^{-1}$ (Jenkins and Bombosch 1995). Equations (12)-(14) are combined to solve for $m^{\prime}$, and thus $T_{b}$. The dimensionless transfer coefficients are given by

$$
\gamma_{T}=\frac{c_{d}^{1 / 2}}{2.12 \ln \left(c_{d}^{1 / 2}|\mathbf{u}| D / \nu_{0}\right)+12.5 \operatorname{Pr}^{2 / 3}-9}
$$

and

$$
\gamma_{S}=\frac{c_{d}^{1 / 2}}{2.12 \ln \left(c_{d}^{1 / 2}|\mathbf{u}| D / \nu_{0}\right)+12.5 \mathrm{Sc}^{2 / 3}-9},
$$

where $\nu_{0}=1.95 \times 10^{-6} \mathrm{~m}^{2} \mathrm{~s}^{-1}$ is the molecular viscosity, $\operatorname{Pr}=13.8$ is the molecular Prandtl number, and $\mathrm{Sc}=2432$ is the molecular Schmidt number of seawater (Jenkins and Bombosch 1995).

\section{f. Frazil nucleation}

When the plume has risen far enough for the increasing in situ freezing point to make it supercooled, frazil ice will nucleate and grow. Ice nuclei must be fairly abundant under ice shelves because the maximum observed supercooling there is only $0.035^{\circ} \mathrm{C}$ (Nicholls and Jenkins 1993; Nicholls et al. 2004), but the exact process of nucleation is uncertain. We follow SJ04 in assuming that dendrite-like platelet ice crystals growing on the ice shelf base may be detached by eddies and suspended in the water column, providing frazil nuclei of a range of sizes. However, we are unable to adopt the exact nucleation strategy of SJ04 because our model is unsteady and multidimensional.

Our frazil nucleation logic is as follows: If a model cell is newly supercooled (i.e., it was not supercooled on the previous time step), we set the concentration of each frazil class in that cell to $C_{S i}=10^{-7}$, where the subscript $S$ indicates "seed," unless it already exceeds that value. We are therefore assuming not only that nuclei always exist, but also that they are distributed evenly over the full range of sizes.

\section{g. Frazil melting and freezing}

Melting and freezing of frazil is modeled by the transfer of a certain number of ice crystals from class $i$ to the size class above $(i+1)$ or below $(i-1)$. Therefore, the rate of change of ice concentration in each size class is determined by the difference in growth (melting) rates between that class and the class below (above). Transfer processes between classes must also be consistent with the movement of crystals of the appropriate volume (SJ04). Therefore, composing $f_{i}^{\prime}$ from ice growth $\left(G_{i}\right)$ and melting $\left(M_{i}\right)$ terms $\left(\mathrm{s}^{-1}\right)$ and integrating over depth, we obtain

$$
\begin{aligned}
f_{i}^{\prime}= & \frac{\rho_{I} D}{\rho_{0}}\left\{\frac{v_{i}}{\Delta v_{i}}\left[(1-H) M_{i+1}+H G_{i}\right]\right. \\
& \left.-\frac{v_{i}}{\Delta v_{i-1}}\left[(1-H) M_{i}+H G_{i-1}\right]\right\},
\end{aligned}
$$

where $v_{i}$ is the volume of a crystal in the $i$ th size class, $\Delta v_{i}=v_{i+1}-v_{i}$, and $H=\operatorname{He}\left(T_{f}-T\right)$ is the Heaviside step function (Holland and Feltham 2005).

Under the assumption that the growth of frazil in turbulent seawater occurs only at the disc edge, is controlled by the turbulent heat flux from the crystal, and has the disc radius as the appropriate length scale for the temperature gradient (Holland et al. 2006), we formulate growth as

$$
G_{i}=\frac{c_{0} \mathrm{Nu}_{i} K_{T}}{\mathcal{L}}\left(T_{f}-T\right) \frac{2}{r_{i}^{2}} C_{i}
$$

and, assuming that melting occurs over the whole crystal surface, melting is

$$
M_{i}=\frac{c_{0} \mathrm{Nu}_{i} K_{T}}{\mathcal{L}}\left(T_{f}-T\right) \frac{2}{r_{i}}\left(\frac{1}{r_{i}}+\frac{1}{2 a_{r} r_{i}}\right) C_{i}
$$

(SJ04). In these expressions $\mathrm{Nu}_{i}$ is the turbulent Nusselt number for each size class, $K_{T}=1.4 \times 10^{-7} \mathrm{~m}^{2} \mathrm{~s}^{-1}$ is the molecular thermal diffusivity, and $r_{i}$ and $a_{r}=0.02$ are the radius and aspect ratio of frazil discs, respectively (SJ04).

We follow Hammar and Shen (1995) in allowing $\mathrm{Nu}_{i}$ to vary with ice crystal size in an attempt to model the effects of turbulence on the heat transfer in each crystal's boundary layer. Holland et al. (2006) note that Hammar and Shen (1995) incorrectly quoted the original formulas for $\mathrm{Nu}_{i}$, so we use the corrected versions,

$$
\mathrm{Nu}_{i}=\left\{\begin{array}{ll}
1+0.17 m^{*} \operatorname{Pr}^{1 / 2} & m_{i}^{*} \leq \frac{1}{\operatorname{Pr}^{1 / 2}} \\
1+0.55 m^{* / 3} \operatorname{Pr}^{1 / 3} & m_{i}^{*}>\frac{1}{\operatorname{Pr}^{1 / 2}}
\end{array},\right.
$$

where $m_{i}^{*}=r_{i} / \eta$ is the ratio between the disc radius and the Kolmogorov length scale $\eta=\left(\nu_{0}^{3} / \epsilon\right)^{1 / 4}$. The turbulent dissipation rate is $\epsilon=7.4 \times 10^{-6} \mathrm{~W} \mathrm{~kg}^{-1}$ so $\eta \approx 1$ $\mathrm{mm}$ in this study. Note that we have truncated the full formulation for $\mathrm{Nu}_{i}$ quoted by Holland et al. (2006), avoiding the need to arbitrarily choose a turbulence 
intensity for the plume, because no frazil crystals in the size classes we use are outside the range of applicability of (20) given this value of $\eta$.

\section{h. Frazil secondary nucleation}

Secondary nucleation is the process whereby new frazil crystal nuclei are detached from "parent" crystals. In this study the formulation of Svensson and Omstedt (1994) is adopted, whereby collision between crystals is assumed to be the detachment mechanism and a proportion of the ice crystals in each size class are converted to "nuclei" (crystals in the smallest class) according to the frequency of crystal collision. The rate of secondary nucleation is proportional to the number of crystal collisions in the volume swept by all crystals in unit time,

$$
\begin{aligned}
n_{1}^{\prime} & =\frac{\rho_{I} D}{\rho_{0}} \sum_{i=2}^{N_{\text {ice }}} \pi \tilde{n} \frac{W_{i}}{r_{i}^{e}} r_{1}^{e^{3}} C_{i} \quad \text { and } \\
n_{i \neq 1}^{\prime} & =-\frac{\rho_{I} D \pi \tilde{n}}{\rho_{0}} \frac{W_{i}}{r_{i}^{e}} r_{1}^{e^{3}} C_{i},
\end{aligned}
$$

where $\tilde{n}$ is the average number of ice crystals of all sizes per unit volume, subject to a maximum value of $10^{3}$, and $r_{i}^{e}$ is an effective radius of frazil discs, equal to the radius of a sphere with the same volume as a disc of radius $r_{i}$. Here $W_{i}$ represents the ice crystal velocity along a path that incorporates both buoyant rising and turbulent motions,

$$
W_{i}^{2}=w_{i}^{2}+\frac{4 \epsilon}{15 \nu_{0}} r_{i}^{e^{2}},
$$

where the frazil rise velocity $w_{i}$ relative to the moving fluid is approximated by frazil's buoyant drift velocity in still water (Gosink and Osterkamp 1983),

$$
w_{i}^{2}=\frac{4\left(\rho_{0}-\rho_{I}\right) g a_{r} r_{i}}{\rho_{0} c_{i}^{d}},
$$

where $c_{i}^{d}$ is a crystal drag coefficient calculated iteratively from the disc Reynolds number (Jenkins and Bombosh 1995).

\section{i. Frazil precipitation}

To represent frazil deposition onto the ice shelf, we adopt the Jenkins and Bombosch (1995) adaptation of the sedimentation parameterization of McCave and Swift (1976), which assumes that the flux of crystals depositing under buoyancy is reduced by turbulence in the boundary layer,

$$
p_{i}^{\prime}=-\frac{\rho_{I}}{\rho_{0}} w_{i} C_{i}\left(1-\frac{|\mathbf{u}|^{2}}{U_{C i}^{2}}\right) \operatorname{He}\left(1-\frac{|\mathbf{u}|^{2}}{U_{C i}^{2}}\right)
$$

In this expression the Heaviside function prevents any erosion from taking place and $U_{C i}$ is a critical plume velocity for each size class above which no precipitation can occur,

$$
U_{C i}^{2}=\frac{0.05\left(\rho_{0}-\rho_{I}\right) g 2 r_{i}^{e}}{\rho_{0} c_{d}}
$$

\section{Results}

In this section we begin by reducing the model to a version that reproduces the results of SJ04, and then introduce our model developments one at a time in order to reveal their modifications to the conclusions of earlier work. We use no-slip and zero scalar flux boundary conditions whenever a solid wall is explicitly introduced, but otherwise it is assumed that all boundaries are open outflows and that gradients in all quantities are zero there. Whenever a simulation includes rotation a latitude of $78^{\circ} \mathrm{S}$ is used, and a time step of $\Delta t=10 \mathrm{~s}$ is required in all simulations to maintain numerical stability of the frazil model. The simplified studies detailed in sections $3 \mathrm{a}-3 \mathrm{~d}$ all use a uniform grid with spacing $\Delta x=250 \mathrm{~m}$, while the more realistic study of section $3 \mathrm{e}$ is run at a coarser resolution, $\Delta x=2 \mathrm{~km}$, as part of a larger study of FRIS. All results are found to display grid independence.

\section{a. One-dimensional model}

To match the results of SJ04, we consider a nonrotating ice shelf with a base that is uniform in the $y$ direction and adopt a uniform plume inflow along the width of the grounding line, thus removing all forcings from the model that could lead to variation in that direction. We match our model to their "linear ice shelf" case, in which the shelf base rises uniformly from a grounding line at 1400-m depth to an ice front of 285-m depth a distance of $600 \mathrm{~km}$ away. The ambient fluid has properties appropriate for the ocean cavity under FRIS: a salinity profile that decreases linearly from $34.71 \mathrm{psu}$ at the grounding line depth to $34.5 \mathrm{psu}$ at the surface, and a temperature rising linearly from $-2.18^{\circ} \mathrm{C}$ at the grounding line to $-1.9^{\circ} \mathrm{C}$ at the surface (Jenkins and Bombosch 1995). Our frazil-sized classes have radii of $0.01,0.05,0.15,0.3,0.4,0.5,0.6,0.8,1$, and $2 \mathrm{~mm}$. We use an inflow of depth $D_{\text {in }}=1 \mathrm{~m}$ that has the properties of meltwater at this depth, $T_{\text {in }}=-2.95^{\circ} \mathrm{C}$, and $S_{\text {in }}=$ $34.42 \mathrm{psu}$ (Gade 1979). We set $A_{h}=K_{h}=0, c_{d}=2.5 \times$ $10^{-3}$, and $\mathrm{Nu}_{i}=1$ to mimic SJ04's parameter choices and we readopt their frazil seeding strategy, in which the nearest supercooled cell to the grounding line has the frazil concentration in each size class fixed to $C_{S i}=4 \times 10^{-9}$. The features distinguishing the two models are then transience (SJ04 use a steady-state 

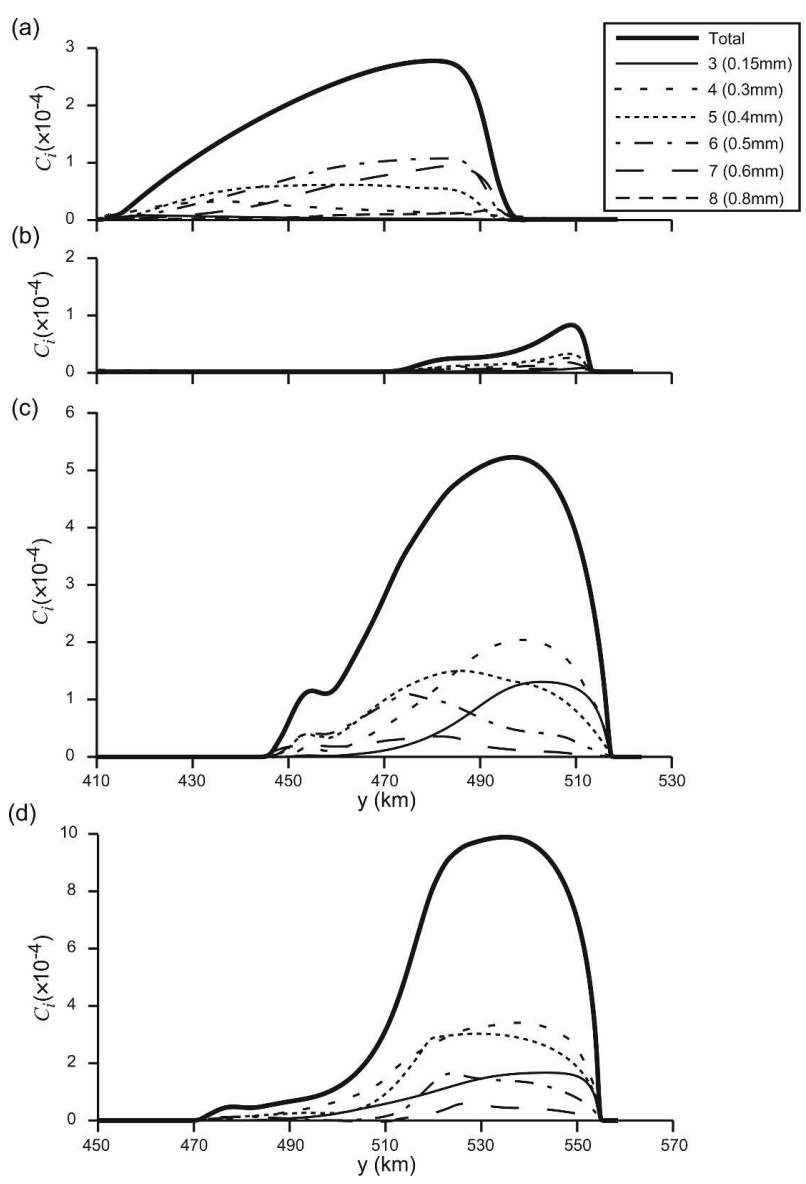

FIG. 3. Frazil ice concentrations resulting from various seeding strategies in one-dimensional simulations. (a) SJ04 seeding strategy after 76 days, (b) our seeding strategy and $C_{S i}=4 \times 10^{-9}$ after 76 days, (c) our seeding strategy and model after 76 days, and (d) our seeding strategy and model after 80 days. In each case the thick line also shows the extent of the plume. Note the different scales in (d).

model) and the formulation of buoyancy forcing and entrainment. We modify the latter by setting $c_{l}=$ 0.01775, which matches $e^{\prime}$ to its counterpart in SJ04 according to Jungclaus and Backhaus (1994).

Figure 3a shows the results of this model after 76 days, when the plume first separates from the ice shelf. This situation is taken to be analogous to the steady state of SJ04 and the frazil concentrations match theirs well. Seeding takes place at approximately $410 \mathrm{~km}$ from the inflow, effectively providing an upstream boundary condition for each frazil class. The total concentration increases with distance downstream because the crystals grow as they move through the supercooled region.

Switching the frazil seeding formulation to our new strategy, but keeping the seed population for each size class at $C_{S i}=4 \times 10^{-9}$, we obtain the results shown in Fig. $3 \mathrm{~b}$ at plume separation. Frazil is seeded at the head
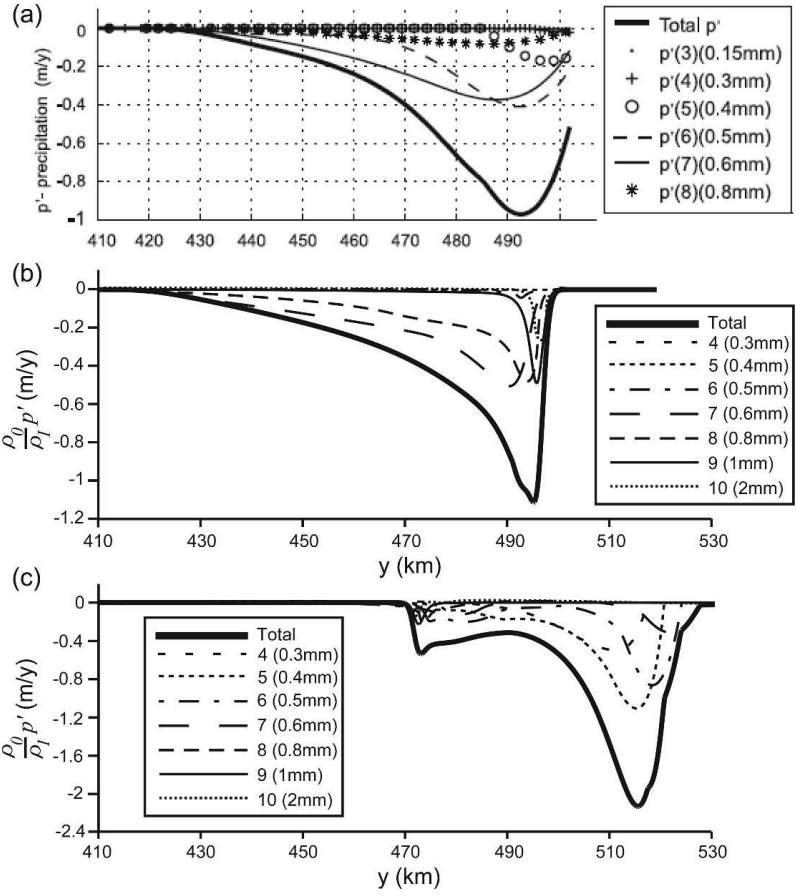

FIG. 4. Frazil precipitation rates $\left(\mathrm{m} \mathrm{yr}^{-1}\right)$ in the onedimensional simulations. (a) Steady-state results from SJ04, (b) results of our SJ04-matching model after 76 days, and (c) results of our chosen model after 80 days. Note the different scale in (c).

of the current as it passes and subsequently grows in response to the crystal dynamics rather than the advection of a fixed upstream population. One consequence of this is that the frazil grows further from the inflow, while the plumes themselves propagate similar distances (as revealed by the extent of the thick lines in Fig. 3).

Figures $3 \mathrm{c}$ and $3 \mathrm{~d}$ show results from our full frazil model, which has the new seeding strategy with $C_{S i}=$ $10^{-7}$ put into each size class and also uses the Holland et al. (2006) formulation for $\mathrm{Nu}_{i}$ [Eq. (20)]. The latter change has a rather small effect but the new seeding results in a significant increase in frazil concentrations, creating a more buoyant plume that separates later at 80 days. Another feature of note is that there is a greater concentration of frazil in the smaller-sized classes; the larger seeding prevents the limitation of growth by a shortage of smaller crystals, a feature of the frazil model discussed fully in Holland and Feltham (2005).

The effects of the changes to the frazil precipitation caused by different seeding formulations are of interest here because they have a bearing on our later claims for the model. Figures $4 \mathrm{a}$ and $4 \mathrm{~b}$ show the frazil precipitation predicted by both SJ04 and our model at the point of separation using SJ04's seeding formulation. The re- 
sults of our SJ04-matching model compare well with the original (Fig. 4b), although our precipitation has a sharper profile, which we attribute to the high spatial and temporal resolution used in this study. A more important difference is that we predict the precipitation of larger frazil crystals than SJ04. This occurs because our plume flows slightly faster than theirs (because of the more sophisticated formulation of buoyancy terms) and its speed exceeds the critical velocity for precipitation of frazil in classes 5 and 6 .

Precipitation in our model using our revised seeding formulation (Fig. 4c) has a larger magnitude and different spatial character than that of SJ04's results. The crystals precipitating at the head of the plume are smaller and a new area of precipitation is found at the rear of the supercooled region, where the largest crystals are located. Both of these features occur because the head of the plume is seeded; the rear of the supercooled region was seeded first and has been supercooled for the longest time, so the frazil population there contains larger crystals that precipitate more readily.

\section{b. Idealized two-dimensional model}

To elucidate the basic two-dimensional behavior of ISW plumes, in this section the full model described in section 2 is used with a wedge-shaped ice shelf. All of the model simplifications of the previous section are removed, but we keep the same ambient fluid properties and frazil size classes. We choose $A_{h}=K_{h}=100$ $\mathrm{m}^{2} \mathrm{~s}^{-1}$ and $\mathrm{c}_{I}=0.012$ in order to obtain the correct frazil precipitation location in subsequent idealized studies (section 3c). The plume starts from an initial mixed layer of temperature $T_{\text {in }}=-2.42^{\circ} \mathrm{C}$, salinity $S_{\text {in }}=34.55 \mathrm{psu}$, depth $D_{\text {in }}=5 \mathrm{~m}$, and width $W_{\text {in }}=10$ $\mathrm{km}$ under an ice shelf that rises from 1100-m depth at the grounding line to $468-\mathrm{m}$ depth at a distance of 200 $\mathrm{km}$ downstream. This geometry is chosen to be representative of the slope of EIS (Fig. 1), as discussed in section 3c. All boundaries are considered to be open apart from on the inflow side, where solid walls represent the grounding line. The modeled plumes do not separate from the ice shelf, so the steady-state results occur after the head of each gravity current has left the domain. In this section we show "snapshots" of results after 30 days of simulation; domain widths are arbitrarily chosen so that the whole wetted area of each plume is contained within the domain after this time.

Figure 5a shows the plume thickness in the nonrotating case. The plume flows directly up the shelf with a speed of approximately $8 \mathrm{~cm} \mathrm{~s}^{-1}$ and tapers from a thick head at the propagating plume front to a shallow plume near the inflow. Model experiments show that frazil concentrations similar to those reported in section 3a can be produced along the centerline of a nonrotating plume of this type.

Figure $5 \mathrm{~b}$ demonstrates the effect of adding Coriolis terms to the momentum balance of a simulation that is otherwise identical to that of Fig. 5a. The flow is nearly geostrophic because basal drag is so low, so Coriolis forces immediately deflect the plume until it flows almost parallel to isobaths of the ice shelf base. The plume flows much more slowly under this new balance (approximately $2 \mathrm{~cm} \mathrm{~s}^{-1}$ ) and it does not propagate far upslope from the inflow region. If ISW plumes do not flow upslope they will not become supercooled or produce any marine ice.

As discussed in section $2 \mathrm{~d}$, this tendency for a model plume to flow along slope is in contradiction to observations (when a reasonable drag coefficient is used) and is due to the neglect of realistic bathymetric features (Jungclaus and Backhaus 1994), Ekman layer effects (Cenedese et al. 2004), and eddies (Jiang and Garwood 1995; Lane-Serff and Baines 1998). The first two effects can be partly reproduced by increasing the drag coefficient to $c_{d}=1.5 \times 10^{-2}$ from the standard value of $c_{d}=1.5 \times 10^{-3}$, and Fig. $5 \mathrm{c}$ shows that this does indeed increase the angle between the plume path and isobaths of the ice shelf base.

\section{c. Simplified Evans Ice Stream ice shelf draft}

In this section we attempt to produce an idealized model of the flow of meltwater underneath the EIS section of FRIS (Fig. 1), and thereby explain the origin of the region of marine ice located near Cape Zumberge. Satellite observations imply that vigorous melting occurs near the grounding line of EIS (Joughin and Padman 2003), so as before we consider the evolution of a plume from a $10-\mathrm{km}$-wide inflow that represents a layer of mixed meltwater and ambient water. The domain is the same as before, apart from a wall running perpendicular to the grounding line, which represents the 135-km-long boundary between EIS inlet and Cape Zumberge. The cape itself is represented as a quartercircle with radius $35 \mathrm{~km}$ (Fig. 6). The topography of the ice shelf base is set such that its isobaths are perpendicular to the wall everywhere, a situation very roughly approximating the real bathymetry in this location (Sandhäger et al.2004); adjacent to the wall the slope of the ice shelf base is the same as that of section $3 \mathrm{~b}$.

The modeled ISW plume does not separate from the shelf, so we examine its properties after 80 days of simulation. The plume immediately turns left from the grounding line under the influence of Coriolis forces, but is impeded by the wall and forced to propagate upslope instead, becoming a very narrow boundary cur- 

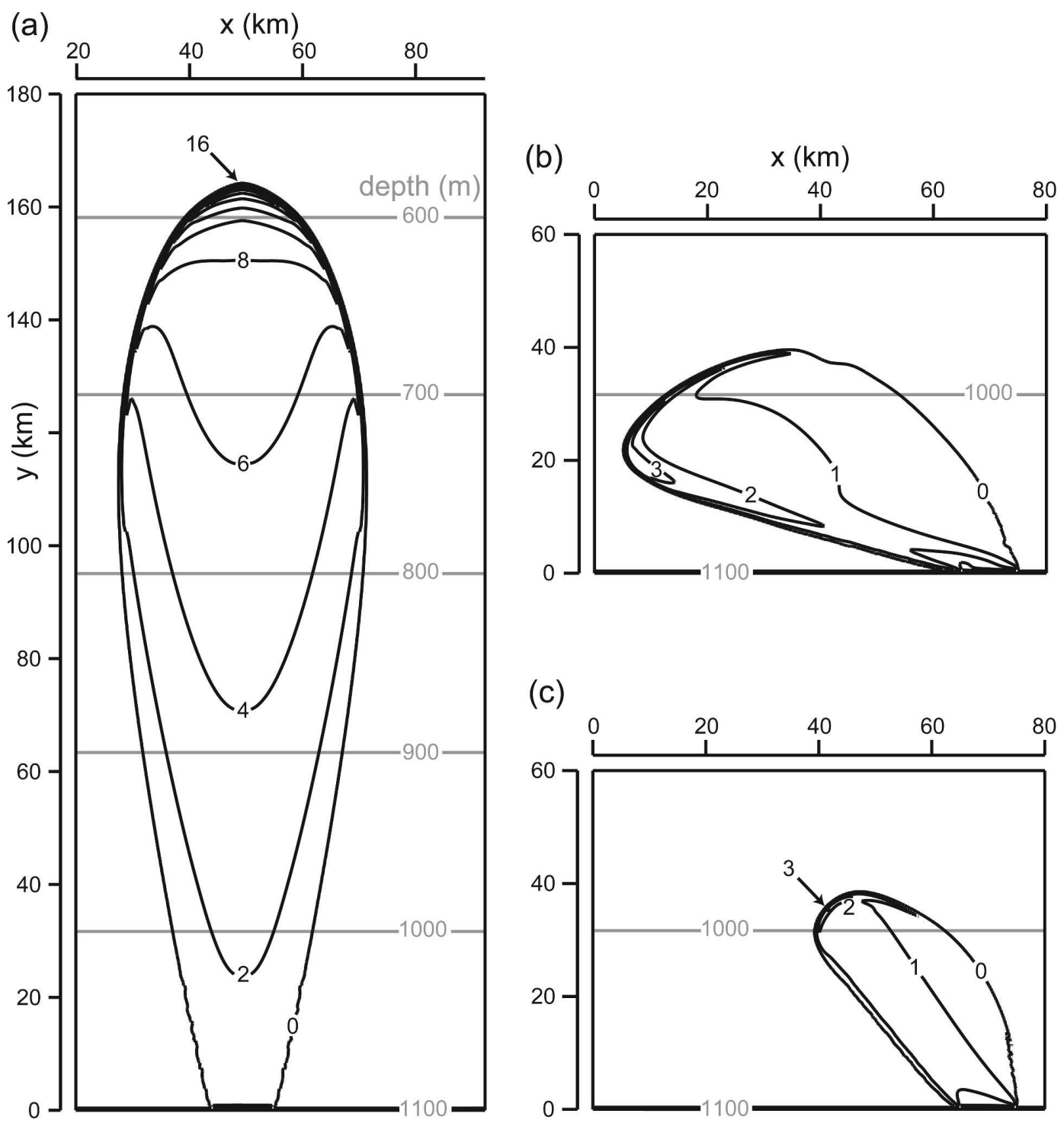

FIG. 5. Contours of plume thickness (m) in the various cases after 30 days of simulation; (a) no rotation, (b) rotation, and (c) rotation and high basal drag $\left(c_{d}=1.5 \times 10^{-2}\right)$.

rent with the ISW banked up against the wall (Fig. 6a). The plume moves slightly more quickly than the geostrophic plume (Fig. 5b) but is still much slower than a nonrotating plume because of the retarding influence of drag from the no-slip wall.

Figure $6 \mathrm{c}$ shows the total basal ice mass transfer, which is composed of melting, direct freezing, and frazil ice precipitation. We predict a basal melting of up to 73 $\mathrm{cm} \mathrm{yr}^{-1}$, a frazil precipitation rate of up to $6.5 \mathrm{~cm} \mathrm{yr}^{-1}$, and a direct freezing rate of up to $0.9 \mathrm{~cm} \mathrm{yr}^{-1}$; according to this model, frazil precipitation dominates direct freezing as a source of marine ice. In comparing these results with Fig. 1, it is seen that the deposition area of marine ice off Cape Zumberge is reproduced surpris- ingly well considering our simplified bathymetry. However, according to observations and other model studies, the actual rates of marine ice formation predicted by the model here are too low by at least an order of magnitude. This is discussed in greater detail in section 3e.

It is important to note the transient behavior of this model. Frazil forms in the head of the plume when it becomes supercooled on first approaching the corner in the wall, after traveling $130 \mathrm{~km}$ in 65 days, and the moving head remains the position of the greatest frazil concentration throughout the whole simulation. The plume continues to flow and precipitate along the wall after traversing Cape Zumberge. This means that we do not find a steady state in which significant precipitation 
(a)

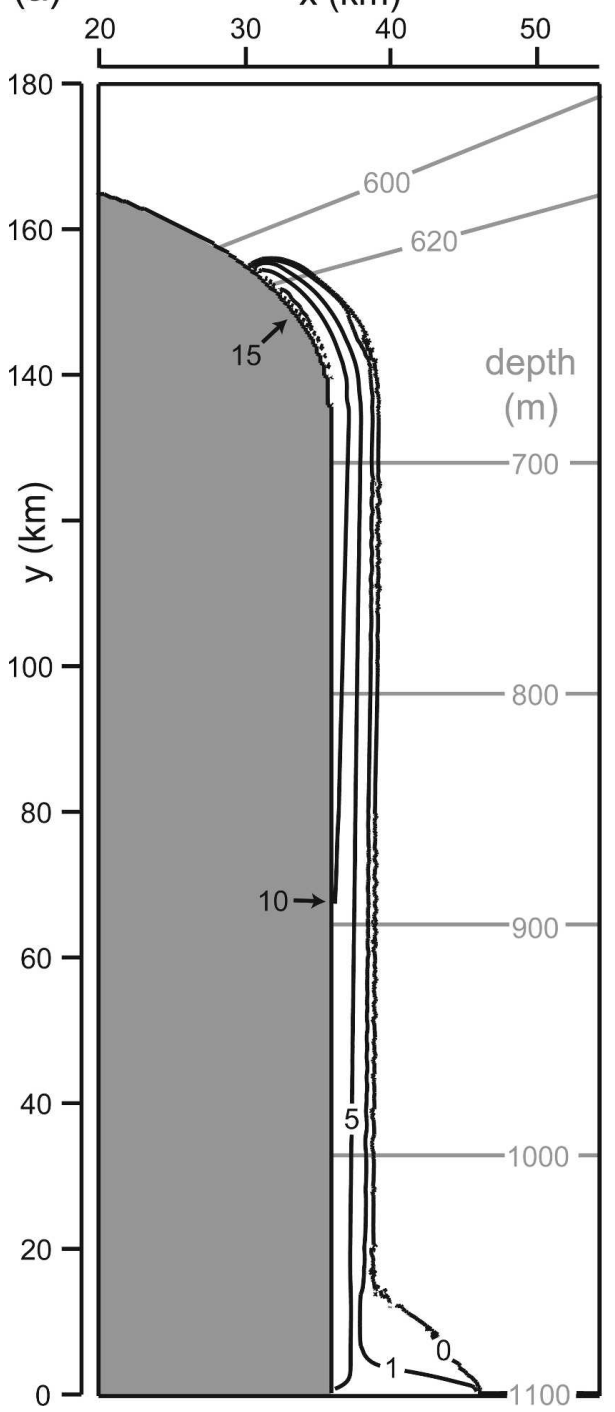

(b)

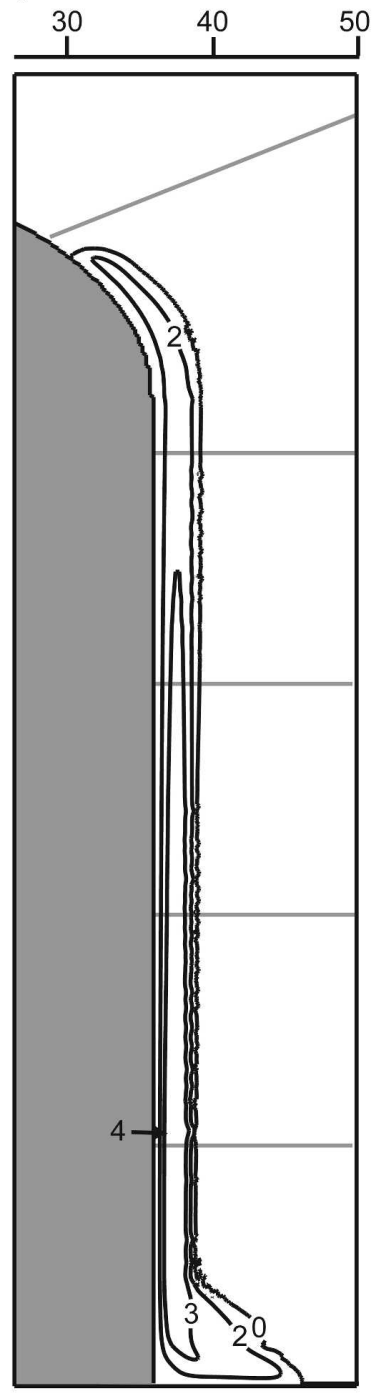

(c)

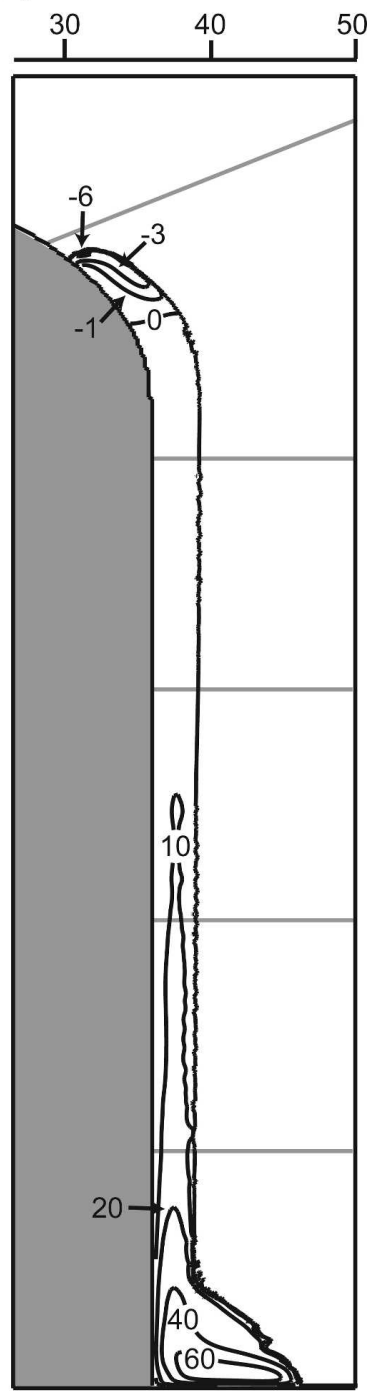

FIG. 6. Results of the simplified EIS case (an idealized rotating plume constrained by a wall) after 80 days. (a) Plume thickness $D(\mathrm{~m})$, (b) plume speed $|\mathbf{u}|\left(\mathrm{cm} \mathrm{s}^{-1}\right)$, and (c) total basal mass transfer $\left(\rho_{0} / \rho_{I}\right)\left(m^{\prime}+p^{\prime}\right)$ (units: $\mathrm{cm}$ $\left.\mathrm{yr}^{-1}\right)$. Note that all plots are stretched in the $x$ direction. The $620-\mathrm{m}$ shelf base isobath marked in (a) represents the section used to assess model sensitivity in Table 1.

occurs in any fixed location, compounding the problem of low marine ice formation rates. Supercooling and frazil formation do continue at the corner of Cape Zumberge once the plume head has passed, but intermittently and with a maximum precipitation rate of only $2 \mathrm{~cm} \mathrm{yr}^{-1}$.

\section{d. Sensitivity studies}

In this section we consider the sensitivity of our model results to variation in the parameters of the model (Table 1), primarily focusing on those relating to the dynamics of the plume rather than the frazil model formulation, which were closely examined by SJ04 and in section 3a. We perform our sensitivity studies on the simplified EIS topography because it provides a clear exposure of the model response to parameter variation; the aim here is to examine the effects of each model component before adopting a more complex topography.

Removing the frazil ice model reveals that frazil has little effect on the plume dynamics because it only influences the flow at a late stage, after the plume has become supercooled. Frazil ice formation accelerates the plume very slightly by increasing its buoyancy, so 
TABLE 1. Model sensitivity to variation in parameters relating to the physics of the plume. The reference simulation has $c_{l}=0.012$, $c_{d}=1.5 \times 10^{-3}, A_{h}=K_{h}=100 \mathrm{~m}^{2} \mathrm{~s}^{-1}, W_{\text {in }}=10 \mathrm{~km}$, and $D_{\text {in }}=5 \mathrm{~m}$. All results are taken from the first day after the head of the plume has passed the 620-m ice shelf base isobath, and $W, \bar{D}$, and $|\overline{\mathbf{u}}|$ are taken across that section (as shown in Fig. 6a). Basal melt and freeze and frazil precipitation rates are calculated as the total ice volume transfer to or from the plume at that time.

\begin{tabular}{|c|c|c|c|c|c|c|c|}
\hline Simulation & Day & $W(\mathrm{~m})$ & $\bar{D}(\mathrm{~m})$ & $\begin{array}{c}|\overline{\mathbf{u}}| \\
\left(\mathrm{cm} \mathrm{s}^{-1}\right)\end{array}$ & $\begin{array}{c}\text { Melt } \\
\left(\mathrm{m}^{3} \mathrm{yr}^{-1}\right)\end{array}$ & $\begin{array}{c}\text { Freeze } \\
\left(\mathrm{m}^{3} \mathrm{yr}^{-1}\right)\end{array}$ & $\begin{array}{c}\text { Precipitation } \\
\left(\mathrm{m}^{3} \mathrm{yr}^{-1}\right)\end{array}$ \\
\hline Reference & 80 & 3.13 & 8.06 & 1.56 & $59 \times 10^{6}$ & $-0.1 \times 10^{6}$ & $-0.4 \times 10^{6}$ \\
\hline No frazil & 80 & 3.13 & 7.98 & 1.51 & $59 \times 10^{6}$ & $-0.4 \times 10^{6}$ & 0 \\
\hline$c_{l}=0.01$ & 85 & 3.13 & 8.01 & 1.30 & $50 \times 10^{6}$ & $-0.1 \times 10^{6}$ & $-5 \times 10^{6}$ \\
\hline$c_{l}=0.014$ & 76 & 3.26 & 8.09 & 1.76 & $76 \times 10^{6}$ & $-0.1 \times 10^{6}$ & $-0.2 \times 10^{6}$ \\
\hline$c_{d}=1.5 \times 10^{-4}$ & 91 & 3.13 & 7.63 & 1.47 & $33 \times 10^{6}$ & $-4 \times 10^{3}$ & $-35 \times 10^{3}$ \\
\hline$c_{d}=1.5 \times 10^{-2}$ & 123 & 3.69 & 11.50 & 0.66 & $67 \times 10^{6}$ & $-1 \times 10^{6}$ & $-0.6 \times 10^{6}$ \\
\hline$A_{h}=K_{h}=50 \mathrm{~m}^{2} \mathrm{~s}^{-1}$ & 57 & 2.70 & 8.07 & 2.45 & $84 \times 10^{6}$ & 0 & 0 \\
\hline$A_{h}^{n}=K_{h}=150 \mathrm{~m}^{2} \mathrm{~s}^{-1}$ & 100 & 3.56 & 7.64 & 1.12 & $53 \times 10^{6}$ & $-0.1 \times 10^{6}$ & $-0.9 \times 10^{6}$ \\
\hline$W_{\text {in }}=5 \mathrm{~km}$ & 95 & 2.92 & 5.85 & 1.32 & $30 \times 10^{6}$ & $-0.1 \times 10^{6}$ & $-0.3 \times 10^{6}$ \\
\hline$W_{\text {in }}=15 \mathrm{~km}$ & 73 & 3.35 & 9.95 & 1.72 & $111 \times 10^{6}$ & $-0.1 \times 10^{6}$ & $-0.6 \times 10^{6}$ \\
\hline$D_{\text {in }}=2.5 \mathrm{~m}$ & 95 & 3.05 & 6.08 & 1.38 & $48 \times 10^{6}$ & $-0.1 \times 10^{6}$ & $-0.2 \times 10^{6}$ \\
\hline$D_{\text {in }}=10 \mathrm{~m}$ & 63 & 3.58 & 11.98 & 1.93 & $85 \times 10^{6}$ & $-0.2 \times 10^{6}$ & $-0.7 \times 10^{6}$ \\
\hline Meltwater inflow & 69 & 3.47 & 11.09 & 1.71 & $45 \times 10^{6}$ & $-0.2 \times 10^{6}$ & $-0.6 \times 10^{6}$ \\
\hline
\end{tabular}

the plume thickens because of additional entrainment. Neglecting frazil has more influence on the thermodynamics of the plume, but we find that the total marine ice deposition is relatively unaffected when the efficient freezing and deposition of frazil ice is removed because in its absence direct freezing onto the ice shelf performs the task of quenching the supercooling present in the plume.

Increasing the entrainment of ambient fluid into the plume by increasing $c_{l}$ widens and thickens the plume, accelerating it because of the relative decrease in the importance of drag. The extra entrainment causes more melting to occur and reduces the amount of marine ice deposition by increasing the superheating and enlarging the area of the plume over which melting takes place. Decreasing $c_{l}$ has the opposite effect.

Varying the basal drag produces slightly more complex results. The plume speed is reduced when the drag is both raised and lowered; in the former case the basal drag simply impedes motion, and in the latter case the tendency of the plume to flow upslope is reduced so that the plume is confined closer to the no-slip wall and lateral drag becomes even more important. In the lowdrag case the narrower and slower plume melts a smaller area less vigorously, becoming supercooled farther from the inflow and thus depositing a smaller volume of marine ice. In the high-drag case the plume becomes supercooled closer to the inflow, so an increase in the total frazil deposition is observed, but the total melting and freezing rates also increase significantly. This occurs because the heat and salt transfer coefficients [(15) and (16)] are functions of the drag coefficient.

Increasing the eddy viscosity $A_{h}$ and eddy diffusivity of heat, salt, and frazil $K_{h}$ smoothes horizontal density gradients and widens the plume, making the gradient of the ambient-plume interface shallower. Both effects decelerate the plume by reducing the buoyancy forcing, which results in less melting and greater marine ice production. This occurs because the entrainment responds nonlinearly to changes in velocity (via the velocity dependence of the turbulent Schmidt number) while the basal melting formulation responds almost linearly; decelerating the plume by reducing its buoyancy decreases the entrainment more than the melting, the plume becomes supercooled sooner as a result, and reduced melting and increased freezing rates ensue. The opposite is true for decreased $A_{h}$ and $K_{h}$.

Because rotation banks the plume up against the wall, increasing the depth of the inflow has a similar effect to increasing its width. Either way, increasing the inflow volume makes the plume deeper, decreasing the overall influence of drag and thus accelerating the plume. The acceleration increases basal melting and freezing and also increases frazil precipitation by producing more supercooling. The nonlinearity of the increase in entrainment detailed in the previous paragraph is diminished by the thickening of the plume (this offsets the velocity-driven increase in $\mathrm{Ri}$, which raises $\left.\mathrm{Sc}_{T}\right)$.

The "meltwater inflow" case has the properties of the initial mixed layer set to ice shelf meltwater rather than equal parts of meltwater and ambient seawater, so its properties are altered to $T_{\text {in }}=-2.72^{\circ} \mathrm{C}$ and $S_{\text {in }}=$ $34.44 \mathrm{psu}$. This accelerates the plume because of the larger density difference between the plume and ambient water, but reduces melting at the ice shelf base because there is less available superheating in the 
(a)

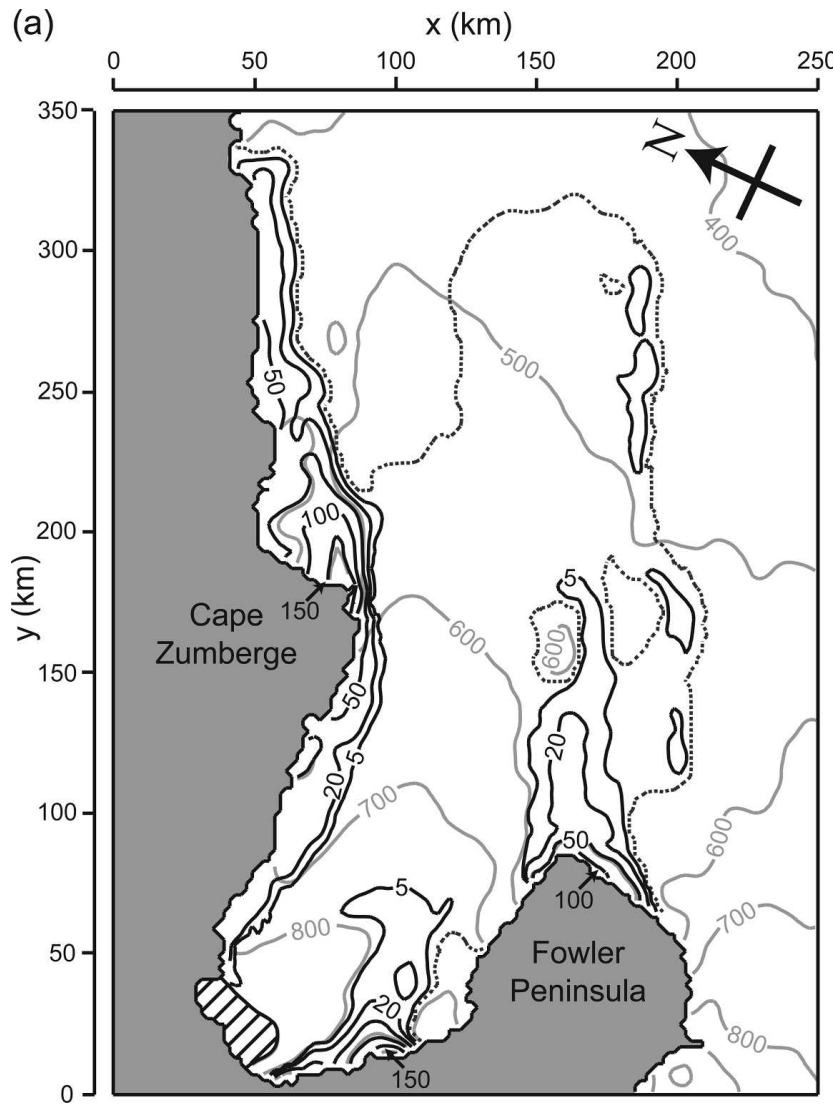

(b)

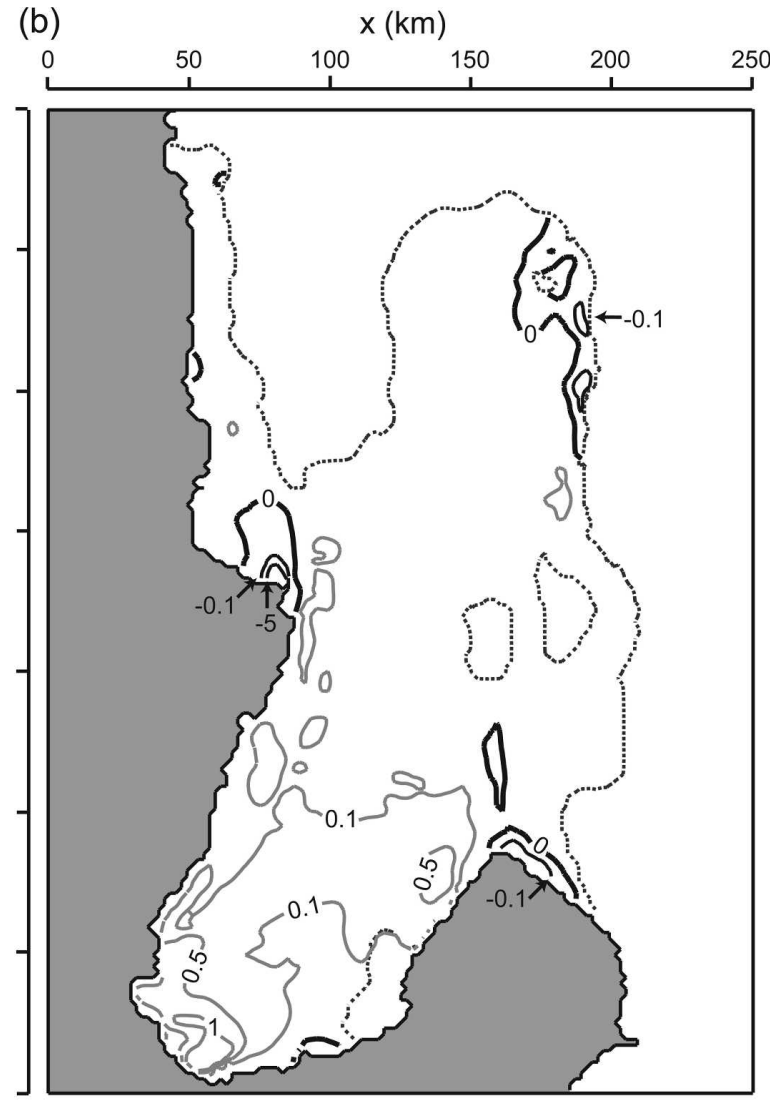

FIG. 7. Results of the model that uses an observed ice shelf draft after 360 days. (a) Plume thickness $D$ (m) and (b) total basal mass transfer $\left(\rho_{0} / \rho_{I}\right)\left(m^{\prime}+p^{\prime}\right)$ (units: $\left.\mathrm{m} \mathrm{yr}^{-1}\right)$. The dotted lines demark the edge of the plume's wetted area, and the inflow area (defined to be the area near the EIS inflow where the ice shelf base is deeper than $900 \mathrm{~m}$ ) is crosshatched in (a).

plume. The plume becomes supercooled sooner and refreezing and frazil precipitation are increased.

\section{e. Observed Evans Ice Stream ice shelf draft}

In this section we present results from a simulation in which the ice shelf topography is defined by the EIS portion of the FRIS draft calculated by Sandhäger et al. (2004) and the grounding line is defined according to the Antarctic Digital Database (ADD Consortium 2002). Three iterations of a $1-8-1$ smoothing routine are applied to the raw draft data to encourage numerical stability (on each iteration, the output value at each node is a 16th of the sum of 8 times that node value and the total of the values at all of the surrounding eight nodes), and the inflow region is chosen to be the area of ice shelf near the EIS grounding line that is deeper than $900 \mathrm{~m}$, as marked on Fig. 7a. The inflow properties vary horizontally according to depth. On this new topography we find that $c_{l}=0.0245$ gives the best fit of model results to observed marine ice distributions and formation rates and, in keeping with the coarser grid resolu- tion, we also use $A_{h}=K_{h}=500 \mathrm{~m}^{2} \mathrm{~s}^{-1}$. All other parameters are kept the same as before. A much fuller analysis of these and related results is in preparation.

In this simulation the plume reaches Cape Zumberge after approximately 100 days, but marine ice formation rates there continue to evolve after the head of the plume has passed, so in Fig. 7 we present results after $1 \mathrm{yr}$ of simulation. Figure $7 \mathrm{a}$ shows that, as before, the plume is banked up against the northern coastline by Coriolis forces, overfilling the inverted "hollows" in the ice shelf base found next to the grounded ice. The plume also flows into other hollows on the southern coastline and offshore of Fowler Peninsula, and an extremely thin layer of the plume flows under the central portion of Ronne Ice Shelf. A closer examination of the depth of the interface between the plume and ambient seawater (not shown) shows that along the entire northern coastline the ISW is piled up against the wall (such that the interface bulges downward), but elsewhere the interface has a relatively constant depth. This confirms the effects of rotation observed in section 3c; Coriolis 
forces generate a strong and thick current on the boundary to the left of the inflow while other areas contain a thin plume everywhere apart from local "pools" of ISW topographically trapped in basal hollows. Plume velocities range up to $5 \mathrm{~cm} \mathrm{~s}^{-1}$ as observed in the idealized case (not shown).

The most striking result from this simulation is its predictions of marine ice formation. Figure $7 \mathrm{~b}$ shows that peak freezing and frazil precipitation rates of 0.4 and $5 \mathrm{~m} \mathrm{yr}^{-1}$, respectively, are obtained near Cape Zumberge. A closer examination of Fig. $7 \mathrm{~b}$ shows that these peak frazil precipitation rates occur in a small area within a larger region of (slower) direct freezing. The model also predicts areas of marine ice formation offshore of Fowler Peninsula and toward the center of Ronne Ice Shelf, both of which agree with the Sandhäger et al. (2004) data in Fig. 1. Joughin and Padman (2003) infer a marine ice formation rate of approximately $5 \mathrm{~m} \mathrm{yr}^{-1}$ near Cape Zumberge, so the agreement of these results with observation is quantitative as well as qualitative. The marine ice formation rates in previous modeling studies (with and without frazil ice) are of the same order (SJ04; Jenkins and Holland 2002a,b), but these models cannot reliably predict the location and rate of frazil ice deposition in this region.

The observations of both Joughin and Padman (2003) and Sandhäger et al. (2004) suggest that our plume adheres to the coastline slightly too closely in the frazil deposition zone. Joughin and Padman (2003) show an area of refreezing stretching approximately $100 \mathrm{~km}$ from Cape Zumberge, and in Fig. 1 marine ice thickness increases in the direction of glaciological flow (implying ice deposition) over the same area. Our plume's deposition zone is narrower than these observations, but it is possible that the frazil deposition off Cape Zumberge might partly result from a meltwater source other than the grounding line of EIS; this will be the subject of further study. In the later stages of the simulation, we are able to match Nicholls et al.'s (2004) finding of supercooled fluid approximately $13 \mathrm{~km}$ from the Orville Coast near the front of Ronne Ice Shelf (not shown).

It should be borne in mind that marine ice is thought to form from consolidation of the layers of frazil slush observed near the ice shelf base (Nicholls and Jenkins 1993; Nicholls et al. 2004), the rate of which is probably governed by the rate of brine rejection from the slush. Frazil precipitation rates, therefore, may not be directly comparable to marine ice accretion rates. In addition, our parameterization of direct basal freezing takes no account of this consolidation process.

This application of the model also suggests that ma- rine ice formation is, to some extent, a transient phenomenon, with marine ice formation rates near Cape Zumberge rising slowly after the plume head has passed and thereafter varying slightly around the rate reported here. This transience is supported by the idea that seasonal pulses of HSSW sink under the ice shelf and intermittently melt ice at the grounding line (Nicholls 1996). The model predicts that an ISW pulse would take around 100 days to traverse the first part of the ice shelf and initiate refreezing. There is no evidence with which to test this time scale, but the modeled current speeds of the order of $5 \mathrm{~cm} \mathrm{~s}^{-1}$ seem to be reasonable under FRIS in general (Nicholls and Østerhus 2004).

\section{Discussion}

We have formulated a new model of ISW plumes and demonstrated its effectiveness in matching observations of marine ice formation rates and locations. The new features of the model and the effects of both rotation and topography have been illustrated by systematically adding components to a one-dimensional nonrotating model used by previous authors. Our final case of a rotating plume under observed FRIS ice shelf topography predicts ice deposition patterns that account for the observed distribution of marine ice near Cape Zumberge in Fig. 1 (Sandhäger et al. 2004) extremely well. The model results also match basal melting and freezing rates inferred from satellite observation (Joughin and Padman 2003).

We find that Coriolis forces are an important influence on ISW plumes, implying that in the absence of upslope transport by eddies they will only become supercooled if steered by an obstruction running perpendicular to isobaths of the ice shelf base. This concept explains the distribution of marine ice under the rest of FRIS (Fig. 1); Fowler Peninsula, Korff Ice Rise, Doake Ice Rumples, and Berkner Island all channel meltwater upslope and account for the nearby freezing zones. We postulate that the significant area of marine ice in the center of Ronne Ice Shelf is a result of Henry Ice Rise steering meltwater from the east, possibly including sections of the grounding line of Filchner Ice Shelf. The refreezing under Filchner Ice Shelf could either originate from melting immediately south of Berkner Island or from grounding line melt steered in the channels in the base of Filchner Ice Shelf.

A natural progression of our study is to incorporate the whole FRIS bathymetry and quantitatively determine the source region and freezing rate for each area of marine ice, extending the results of section $3 \mathrm{e}$ and analyzing them in more detail. Transience could also be 
studied by varying the mixed layer at the grounding line, which initiates our model plumes. This work forms the basis of a study in progress. After this it is important to try and determine the importance of eddying on the upslope transport of ISW, which can only be done using a model with more vertical layers. In the meantime, several aspects of the current model could also warrant further investigation. The detailed structure of the Ekman layer could be represented, because this affects upslope drainage. The processes involved in plume separation could be modeled, although there is little experimental or observational data for this. The slush layer and its consolidation process could be represented in the parameterization of direct basal freezing. Last, very little is known about the melting at grounding lines that provides the initial impetus for these plumes. Despite these shortcomings, the model presented in this study reproduces observed features of FRIS well enough for us to be confident in its emphasis of the important effects of rotation and topography on ISW plumes.

Acknowledgments. We are grateful to Johann Jungclaus for allowing us to examine the source code for his plume model and to Henner Sandhäger for the FRIS topography data and map of marine ice thickness.

\section{REFERENCES}

ADD Consortium, cited 2002: Antarctic Digital Database, version 4.0. SCAR. [Available online at http://www.add.scar.org/.]

Ashton, G. D., and J. F. Kennedy, 1972: Ripples on the underside of river ice covers. J. Hydraul. Div. Amer. Soc. Civ. Eng., HY9, 1603-1624.

Beckmann, A., H. H. Hellmer, and R. Timmermann, 1999: A numerical model of the Weddell Sea: Large-scale circulation and water mass distribution. J. Geophys. Res., 104, $23375-$ 23391.

Bo Pederson, F., 1980: Dense bottom currents in rotating ocean. J. Hydraul. Div. Amer. Soc. Civ. Eng., 106, 1291-1308.

Cenedese, C., J. A. Whitehead, T. A. Ascarelli, and M. Ohiwa, 2004: A dense current flowing down a sloping bottom in a rotating fluid. J. Phys. Oceanogr., 34, 188-203.

De Angelis, H., and P. Skvarca, 2003: Glacier surge after ice shelf collapse. Science, 299, 1560-1562.

Feltham, D. L., and M. G. Worster, 1999: Flow-induced morphological instability of a mushy layer. J. Fluid Mech., 391, 337357.

Foldvik, A., and Coauthors, 2004: Ice shelf water overflow and bottom water formation in the southern Weddell Sea. J. Geophys. Res., 109, C02015, doi:10.1029/2003JC002008.

Gade, H. G., 1979: Melting of ice in sea water: A primitive model with application to the Antarctic ice shelf and icebergs. $J$. Phys. Oceanogr., 9, 189-198.

Gosink, J. P., and T. E. Osterkamp, 1983: Measurements and analyses of velocity profiles and frazil ice-crystal rise velocities during periods of frazil-ice formation in rivers. Ann. Glaciol., 4, 79-84.
Grosfeld, K., R. Gerdes, and J. Determann, 1997: Thermohaline circulation and interaction between ice shelf cavities and the adjacent open ocean. J. Geophys. Res., 102, 15 595-15 610.

Hammar, L., and H. T. Shen, 1995: Frazil evolution in channels. $J$. Hydraul. Res., 33, 291-306.

Hellmer, H. H., and D. J. Olbers, 1989: A two-dimensional model for the thermohaline circulation under an ice shelf. Antarc. Sci., 1, 325-336.

Holland, D. M., and A. Jenkins, 1999: Modeling thermodynamic ice-ocean interactions at the base of an ice shelf. J. Phys. Oceanogr., 29, 1787-1800.

Holland, P. R., and D. L. Feltham, 2005: Frazil dynamics and precipitation in a water column with depth-dependent supercooling. J. Fluid Mech., 530, 101-124.

— _ _ , and S. F. Daly, 2006: On the Nusselt number for frazil ice growth-A correction to "Frazil evolution in channels" by Lars Hammar and Hung-Tao Shen. J. Hydraul. Res., in press.

Jenkins, A., 1991: A one-dimensional model of ice shelf-ocean interaction. J. Geophys. Res., 96, 20 671-20 677.

_ - and A. Bombosch, 1995: Modelling the effects of frazil ice crystals on the dynamics and thermodynamics of Ice Shelf Water plumes. J. Geophys. Res., 100, 6967-6981.

_ , and D. M. Holland, 2002a: A model study of ocean circulation beneath Filchner-Ronne Ice Shelf, Antarctica: Implications for bottom water formation. Geophys. Res. Lett., 29, 1193, doi:10.1029/2001GL014589.

_, and _ 2002b: Correction to "A model study of ocean circulation beneath Filchner-Ronne Ice Shelf, Antarctica: Implications for bottom water formation" by Adrian Jenkins and David M. Holland. Geophys. Res. Lett., 29, 1634, doi:10.1029/2002GL015647.

Jiang, L., and R. W. Garwood, 1995: A numerical study of threedimensional dense bottom plumes on a Southern Ocean continental slope. J. Geophys. Res., 100, 18 471-18 488.

Joughin, I., and L. Padman, 2003: Melting and freezing beneath Filchner-Ronne Ice Shelf, Antarctica. Geophys. Res. Lett., 30, 1477, doi:10.1029/2003GL016941.

_- W. Abdalati, and M. Fahnestock, 2004: Large fluctuations in speed on Greenland's Jakobshavn Isbræ glacier. Nature, 432, 608-610.

Jungclaus, J. H., and J. O. Backhaus, 1994: Application of a transient reduced gravity plume model to the Denmark Strait outflow. J. Geophys. Res., 99, 12 375-12 396.

_ _ _ - and H. Fohrmann, 1995: Outflow of dense water from the Storfjord in Svalbard: A numerical model study. J. Geophys. Res., 100, 24 719-24 728.

Killworth, P. D., 1977: Mixing on the Weddell Sea continental slope. Deep-Sea Res., 24, 427-448.

__ , and N. R. Edwards, 1999: A turbulent bottom boundary layer code for use in numerical ocean models. J. Phys. Oceanogr., 29, 1221-1238.

Kochergin, V. P., 1987: Three-dimensional prognostic models. Three-Dimensional Coastal Ocean Models, N. S. Heaps, Ed., Coastal and Estuarine Studies Series, Vol. 4, Amer. Geophys. Union, 201-208.

Lambrecht, A., C. Meyer, H. Oerter, and U. Nixdorf, 1999: Investigations of the mass balance of the southeastern Ronne Ice Shelf, Antarctica. Ann. Glaciol., 29, 250-254.

Lane-Serff, G. F., and P. G. Baines, 1998: Eddy formation by dense flows on slopes in a rotating fluid. J. Fluid Mech., 363, 229-252.

Lewis, E. L., and R. G. Perkin, 1983: Supercooling and energy 
exchange near the Arctic Ocean surface. J. Geophys. Res., 88, 7681-7685.

MacAyeal, D. R., 1984: Numerical simulations of the Ross Sea tides. J. Geophys. Res., 89, 607-615.

_ 1985: Evolution of tidally triggered meltwater plumes below ice shelves. Oceanology of the Antarctic Continental Shelf, S. S. Jacobs, Ed., Antarctic Research Series, Vol. 43, Amer. Geophys. Union, 133-143.

McCave, I. N., and S. A. Swift, 1976: A physical model for the rate of deposition of fine-grained sediments in the deep sea. Geol. Soc. Amer. Bull., 87, 541-546.

Mellor, G. L., and P. A. Durbin, 1975: The structure and dynamics of the ocean surface mixed layer. J. Phys. Oceanogr., 5, 718728.

Nicholls, K. W., 1996: Temperature variability beneath Ronne Ice Shelf, Antarctica, from thermistor cables. J. Geophys. Res., 101, 1199-1210.

1997: Predicted reduction in basal melt rates of an Antarctic ice shelf in a warmer climate. Nature, 388, 460-462.

, and A. Jenkins, 1993: Temperature and salinity beneath Ronne Ice Shelf, Antarctica. J. Geophys. Res., 98, 22553 22568.

— tion timescales in the ocean cavity beneath Filchner-Ronne Ice Shelf, Antarctica. J. Geophys. Res., 109, C04014, doi:10.1029/2003JC002149.

_, K. Makinson, and S. Østerhus, 2004: Circulation and water masses beneath the northern Ronne Ice Shelf, Antarctica. $J$. Geophys. Res., 109, C12017, doi:10.1029/2004JC002302.

Nøst, O. A., and A. Foldvik, 1994: A model of ice shelf-ocean interaction with application to the Filchner-Ronne and Ross Ice Shelves. J. Geophys. Res., 99, 14 243-14 254.

Oerter, H., J. Kipfstuhl, J. Determann, H. Miller, D. Wagenbach, A. Minikin, and W. Graf, 1992: Evidence for basal marine ice in the Filchner-Ronne Ice Shelf. Nature, 358, 399-401.
Orsi, A. H., G. C. Johnson, and J. L. Bullister, 1999: Circulation, mixing, and production of Antarctic Bottom Water. Progress in Oceanography, Vol. 43, Pergamon, 55-109.

Payne, A. J., A. Vieli, A. P. Shepherd, D. J. Wingham, and E. Rignot, 2004: Recent dramatic thinning of largest West Antarctic ice stream triggered by oceans. Geophys. Res. Lett., 31, L23401, doi:10.1029/2004GL021284.

Ramming, H.-G., and Z. Kowalik, 1980: Numerical Modelling of Marine Hydrodynamics. Elsevier, 369 pp.

Rivaro, P., R. Frache, A. Bergamasco, and R. Hohmann, 2003: Dissolved oxygen, NO and PO as tracers for Ross Sea Ice Shelf Water overflow. Antarc. Sci., 15, 399-404.

Sandhäger, H., D. G. Vaughan, and A. Lambrecht, 2004: Meteoric, marine and total ice thickness maps of Filchner-RonneSchelfeis, Antarctica. FRISP Rep. 15, L. H. Smedsrud, Ed., Bjerknes Centre for Climate Research, Bergen, Norway, 23-39.

Shepherd, A. P., D. J. Wingham, A. J. Payne, and P. Skvarca, 2003: Larsen ice shelf has progressively thinned. Science, 302, 856-859.

- , - and E. Rignot, 2004: Warm ocean is eroding West Antarctic Ice Sheet. Geophys. Res. Lett., 31, L23402, doi:10.1029/2004GL021106.

Smedsrud, L. H., and A. Jenkins, 2004: Frazil ice formation in an Ice Shelf Water plume. J. Geophys. Res., 109, C03025, doi:10.1029/2003JC001851.

Svensson, U., and A. Omstedt, 1994: Simulation of supercooling and size distribution in frazil ice dynamics. Cold Reg. Sci. Technol., 22, 221-233.

Taylor, G. I., 1920: Tidal friction in the Irish Sea. Philos. Trans. Roy. Soc. London, 220A, 1-33.

Thomas, R. H., 2004: Force-perturbation analysis of recent thinning and acceleration of Jakobshavn Isbræ, Greenland. $J$. Glaciol., 50, 57-66. 